\title{
ENTRE IDIOMAS OCIDENTAIS E O CHINÊS: O IMPÉRIO DOS SIGNIFICADOS NA TRADUÇÃO DA POESIA, A EXEMPLO DE MAO DUN
}

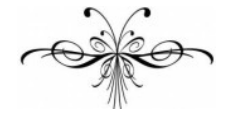 \\ RAQUEL ABI-SÂMARA
}

\begin{abstract}
Aplicada às obras, a cesura platônica sanciona um certo tipo de "traslação", a do "sentido" considerado como um ser em si, como uma pura idealidade, como um certo "invariante" que a tradução faz passar de uma língua a outra deixando de lado sua casca sensível, seu “corpo”: de sorte que o insignificante, aqui, é antes o significante. (Berman, 2007:32)
\end{abstract}

Resumo: Com bases na análise do texto "Some thoughts on translating poetry”, escrito em 1922 por Mao Dun, importante escritor chinês e promotor da Nova Literatura na China, este artigo convida o leitor a uma reflexão sobre a tradução platônica (Berman, 2007) praticada na poesia ocidental traduzida para o chinês, no contexto do Movimento da Nova Cultura na China. Dadas as origens linguísticas notavelmente distintas entre o chinês e idiomas indo-europeus, parte-se do princípio da impossibilidade (ou da remota possibilidade) de recriação acústico-sonora de versos de um idioma (ocidental) a outro (chinês), e vice-versa, e com isso privilegia-se a tradução semântica (ou a tradução por sentido).

Palavras-chave: poesia chinesa; tradução platônica; aspectos sonoros na tradução de poesia.

\begin{abstract}
Departing from the analysis of the essay "Some thoughts on translating poetry“, written in 1922 by Mao Dun - an important Chinese writer and promoter of the so called New Literature in China -, this article invites the reader to reflect on the concept of Platonic translation (Berman, 2007) practiced by translators of Western poetry into Chinese in the context of the New Culture Movement in China. Given the remarkably different origins of Chinese and Indo-European languages, we depart from the principle that it is impossible (or remotely possible) to recreate the acoustic effects of verses from one language (western) into another (Chinese) and vice versa, and because of that semantic translation (or translation according to sense) is dominant.
\end{abstract}

Keywords: Chinese poetry; Platonic translation; sound aspects in poetry translation. 
$1 \begin{aligned} & \text { antologia Twentieth-Century Chinese Translation Theory } \\ & \text { (Chan, 2004), organizada por Leo Tak-hung Chan, reúne } \\ & \text { relevantes polêmicas e artigos teóricos sobre tradução, escritos }\end{aligned}$ por renomados tradutores e autores chineses ao longo do século XX na China. Um dos oito capítulos que compõem o livro focaliza especificamente a tradução da poesia ocidental para o chinês, sob o título "The untranslatability of poetry", composto por quarto artigos: dois da década de 1920, escritos por autores significativos no processo de renovação da literatura chinesa, além de dois artigos mais recentes, um do final da década de 1980, e outro de 1990 . O presente artigo vai analisar, à luz de Antoine Berman, o primeiro texto desse capítulo, intitulado "Some thoughts on translating poetry" (1922), de Mao Dun, importante escritor chinês e promotor da Nova Literatura na China. ${ }^{1}$

Mao Dun (1896-1981), pseudônimo de Shen Dehong (Shen Yanbing) ${ }^{2}$, reconhecido como um dos maiores escritores realistas da China, foi crítico cultural e jornalista, e atuou como Ministro da Cultura na China, de 1949 a 1965, desde a fundação da República Popular da China (RPC) até as vésperas da Revolução Cultural (1966-1976), quando foi destituído do cargo por motivo de ruptura ideológica. Mao Dun participou ativamente do Movimento da Nova Cultura na China, no começo do século XX, que promoveu, entre outras ações, a importação da literatura ocidental e sua tradução. ${ }^{3}$ Em 1917, Mao Dun começou a trabalhar como editor assistente na revista Xuesheng Zazhi (revista dos estudantes), onde escreveu dois artigos significantes para a conscientização política dos estudantes universitários na China. Em 1920, já era reconhecido como romancista. Nessa ocasião, Mao Dun e um grupo de jovens escritores chineses assumem a direção da revista Xiaoshuo Yuebao (Monthly Fiction), e passam a publicar literatura ocidental (Tolstoi, Checkov, Balzac, Flaubert, Zola, Byron, Keats etc) e a divulgar novas teorias da literatura. Ainda nesse ano, torna-se editor-chefe da revista Xiaoshuo Yuebao, tendo que reformá-la completamente, em resposta ao Movimento da Nova Cultura, que começa a acontecer a partir do conhecido Quatro de Maio de 1919, grande marco de virada política e cultural na China, desencadeado pelo protesto dos estudantes nas ruas, a reivindicarem mudanças políticas e sociais, e a refutarem valores tradicionais, confucianos. Esse movimento é tido por muitos historiadores como o início do Partido Comunista Chinês, e, por extensão, da República Popular da China. A revista reformulada por Mao Dun, Xiaoshuo Yuebao, tornou-se um sucesso de venda, cerca de 10 mil cópias por mês, e contribuiu muito para a continuidade do Movimento da Nova Cultura.

No artigo "Some thoughts on translating poetry" (1922), Mao Dun expõe questões gerais, tais como: a tradução de poesia estrangeira é “possível”?

\footnotetext{
${ }^{1}$ Como se sabe, a Nova Literatura chinesa privilegiou, em sua gênese, a tradução sistemática de obras da literatura universal, realizada nas primeiras décadas do século XX.

${ }^{2}$ As informações sobre Mao Dun foram retiradas de <http://en.wikipedia.org/wiki/Mao_Dun>, em consulta feita em 26 de junho de 2013.

3 "Calcula-se que durante a década de 1920 mais de trinta países tenham tido seus trabalhos traduzidos para a língua chinesa. Em 1935, a esquerda liberal chinesa recrutou os mais renomados tradutores da nação para um mutirão tradutório sob as ordens do renomado editor Zheng Zhenduo (1898-1958), com o objetivo de traduzir e publicar, no período de dois anos, 1935-1936, mais de cem clássicos de mais de uma dezena de países, criando a biblioteca mundial, a qual reuniria grande parte da literatura antiga, medieval e moderna dos mais influentes países estrangeiros da época.” In: http://www.maxwell.lambda.ele.puc-rio.br/1672/16727_3.pdf
} 
Os tradutores devem seguir regras ao traduzirem poesia estrangeira? Qual a "vantagem" de se traduzir poesia estrangeira, ou, em outras palavras, "por que traduzir poesia estrangeira?" Sobre a traduzibilidade da poesia, o autor destaca três posições elementares: a opinião de que poesia estrangeira é traduzível, a opinião contrária, de que não se pode traduzi-la, e a opinião de que há algumas coisas que não podem absolutamente ser traduzidas, e nesse caso o tradutor tem de fazer um tipo de improviso, não mais do que isso. Desta última posição compartilha Mao Dun. Por mais competente que um tradutor seja, como vai afirmar, e, por mais que aproxime sua tradução do texto fonte, "não conseguirá mais do que recontar ${ }^{4}$ o poema, que jamais poderá ser visto como o original” (Mao, 2004:203):

Somente uma ou duas das forças [strengths] totais do poema original podem ser preservadas na tradução, e o todo jamais poderá ser preservado. Portanto, traduzir poesia não é o mesmo que copiar uma pintura. Ao copiar uma pintura, é possível expressar todas as forças do original em uma cópia detalhada, mas traduzir um poema nunca poderá ser assim. Se o tradutor forçar a cópia, o resultado final será um desperdício de energia, e o texto traduzido não terá valor.

O uso dos termos "recontar” e “copiar” revelam entendimentos implícitos de Mao Dun com relação à tradução de poesia. Se o bom tradutor consegue, no melhor das hipóteses, "recontar" o poema original, observa-se que a abordagem tradutória de Mao privilegia, no final das contas, a interpretação semântica, a interpretação da "narrativa" do poema fonte, daquilo essencialmente que o poema “diz". Sua visão do poema traduzido não recai no poema como uma unidade (em paralelo com a unidade do original) entre aquilo o que se diz e o modo como se diz. O que Mao chama de "forças" do poema original (apenas uma ou duas forças) passíveis de serem preservadas na tradução pode ser talvez entendido como momentos raros de unidade forma/sentido entre um poema e outro (original e "cópia”). Entende-se que, embora Mao não formule deste modo, dada a impossibilidade de verter certas singularidades rítmicas ou musicais do poema construídas a partir de aspectos específicos do idioma fonte, o autor crê que o melhor que se poderia conseguir seria "recontar" o que foi "contado" no poema de partida, em suma, excluindo-se aí o ofício do verso, restringindo-se em transmitir apenas o "teor" da "mensagem". No entanto, nem todo poema é narrativo, nem todo poema tem como foco principal seus valores semânticos, principalmente quando se trata da poesia moderna. Não raro, os sentidos resultam do jogo entre as formas, da disposição gráfica dos versos no papel, da justa amarração entre o que se diz e o como se diz.

Mesmo ao admitir que a tradução de um poema não é o mesmo que a cópia de uma pintura, o autor parte dessa comparação, ou seja, da ideia de tradução como cópia (e não como recriação), e daí a impossibilidade de se fazer

\footnotetext{
${ }^{4}$ No texto em inglês, o verbo que aparece é "re-telling”, com uma nota do tradutor, Brian Holton, explicando que no original, em chinês, Mao Dun usa a expressão “retold”. Outros termos escritos originalmente em inglês por Mao Dun são preservados pelo tradutor, com destaque em letras itálicas. Note-se que a adoção de termos em inglês pelo autor demonstra, em certa medida, sua abertura para a influência de línguas, e, por extensão, de culturas estrangeiras sobre a sua própria língua e cultura.
} 
uma tradução do poema como um todo, em sua unidade de formas e sentidos, a não ser que se pudesse “copiar” não somente aquilo que é "narrado”, como também os sons e os jogos fônicos do poema exatamente como são no original, o que poderia acontecer somente de modo ficcional, irônico e bem humorado, como sugere Jorge Luis Borges em seu conto "Pierre Menard, autor del Quijote”, em que o escritor francês fictício, Menard, faz uma tradução tão perfeita do original de Cervantes que, no final das contas, sua tradução é o próprio texto de Cervantes, coincidência absoluta, com as mesmas palavras, ipsis literis.

No entanto, seria injusto não enxergar no posicionamento de Mao Dun uma certa margem de criação, de liberdade do tradutor de poesia, pois entende que os elementos intraduzíveis em um poema podem ser, como diz, "improvisados” na tradução, ainda que de modo distanciado do poema fonte. Forçar o resultado de um poema para fazê-lo o mais próximo possível do original, como afirma Mao, é torná-lo um poema sem valor. O autor vai ainda além, e radicaliza seu posicionamento ao afirmar que: “[a] situação é mais óbvia na tradução de poesia ocidental 'metrificada'. Para dizer a verdade, a tradução de poesia estrangeira é feita porque não há alternativa. É melhor do que nada” (Mao, 2004:203).

Apesar das impossibilidades constantes e da diminuição qualitativa da poesia ocidental traduzida para a língua chinesa, Mao Dun a considera positiva para a revitalização da literatura naquele momento de renovação política, cultural e literária na China. Nesse sentido, as reflexões de Mao Dun sobre a tradução de poesia na China anteveem, cerca de 50 anos antes, a Teoria dos Polissistemas desenvolvida por Ithamar Even-Zohar no contexto da tradução literária para o idioma hebraico. Na perspectiva de Mao, a tradução vai muito além do âmbito linguístico-filológico, e seus efeitos são avaliados em termos de relações entre culturas, os efeitos da cultura e da literatura de partida sobre a cultura e literatura de chegada, num momento de renovação e busca de definição de uma literatura nacional na China. "Qual a vantagem de se traduzir poesia estrangeira?”, pergunta-se Mao Dun.

Se a tradução de poesia estrangeira não consistir em algo significativo, mas somente num jogo literário, então não há necessidade de levar adiante essa questão. Se ela não for mais do que 'um relato sobre que tipos de flores há nos jardins estrangeiros, e quais são as flores novas que estão desabrochando', então a questão não merece um estudo sério. Mas, se a tradução for feita porque há determinadas obras de arte da literatura universal que não podemos fazer a não ser em versões traduzidas, então a questão merece atenção. Eu penso que a tradução de poesia estrangeira é muito positiva.

É isso: a tradução de poesia estrangeira pode ser um meio de revitalização de nossa própria poesia. Se considerarmos a história literária de outros países, veremos com frequência que a introdução de um texto traduzido eletrifica a história literária de um país em novas direções, ao menos na arena poética deve ocorrer uma influência dessa espécie.

Desse ponto de vista, a tradução de poesia é muito significativa para o mundo literário, e ainda mais significativa para uma nação que esteja desenvolvendo uma nova literatura. (Mao, 2004:204) 
Suas avaliações sobre a tradução não se restringem somente à poesia, abrangem também a tradução de romances e de narrativas literárias, que contribuem para a emergência de uma nova literatura nacional. Segundo Mao, esse fenômeno ocorreu na Rússia, Tchekoslováquia, Polônia etc, o que se pode ilustrar com a leitura das histórias literárias contemporâneas desses países. Dada a relevância da tradução de poesia estrangeira para o idioma chinês no contexto da segunda década do século XX, Mao complementa uma das questões que levanta logo ao início do texto: "Como a tradução de poesia estrangeira é algo significativo, não podemos nos limitar somente a discutir se ela é 'possível ou impossível: nós temos de fazê-la, mesmo que ela não possa ser feita, e devemos ser realistas em nossas discussões sobre os métodos de tradução” (Mao, 2004: 204).

Ao propor métodos para a tradução de um poema, Mao Dun posicionase de modo nitidamente platônico, conforme a definição de Antoine Berman (Berman: 2007) para tradução platônica e idealista, como aquela que considera o sentido de um texto como algo central, nuclear, e ignora assim a literalidade, o corpo sensível de um texto literário. Certamente que a tradução à letra defendida por Berman (que não caberia detalhar aqui) é algo muito mais complexo e multifacetado do que o entendimento de "tradução literal" de Mao Dun, à qual este claramente se opõe. "A poesia deve ser traduzida literalmente ou deve ser parafraseada?”, pergunta-se Mao Dun, que vai buscar a resposta numa citação de Sir John Denham, onde se lê uma defesa explícita pela tradução do sentido na tradução da poesia. Para Denham, o Fides Interpres pode funcionar bem para assuntos factuais e também para "assuntos de fé" (leia-se textos religiosos ou textos sensíveis), mas não para matéria de poesia. Como vai dizer Denham: "a poesia é feita de um espírito tão sutil que evapora ao ser vertida de uma língua a outra. E se um novo espírito não for adicionado nesta transfusão, não restará nada a não ser um caput mortuum...” (apud Mao, p. 204). Mao escreve:

Eu aprovo a tradução do sentido (sense translation). Numa tradução do sentido, ao contrário da tradução literal do tipo que ele [Denham] chama de Fides Interpres (...), o tradutor não traduz o texto com o seu [do tradutor] próprio sentido, mas sim com o sentido do autor. Em outras palavras, [a tradução por sentido] é um método que consegue preservar o “espírito” do original. (Mao, 2004:204)

Preservar o "espírito" do original numa tradução de poesia é uma tarefa no entanto pouco objetiva e demasiadamente etérica (o que é necessariamente o "espírito" de um poema?). Se o "espírito" do poema for o "sentido” dado ao texto pelo poeta, aí entramos em uma questão delicada de interpretação. Na condição de leitores, de críticos literários, de intérpretes ou de tradutores, será possível captar "o sentido", a intenção autoral do poeta do texto original? Se considerarmos o receptor/tradutor do poema, assim como o autor do poema na língua de partida, como sujeitos históricos que realmente são, como na concepção histórico-materialista de Henri Meschonnic (Pour la Poétique II. Épistémologie de l'Écriture - Poétique de la Traduction, 1973), toda interpretação de texto literário estará sujeita a vetores espaço-temporais que serão determinantes na recriação dos sentidos possíveis desse texto. Falar-se de intenção autoral é algo bastante datado, relacionado ao final do século XVIII e século XIX, às noções ro- 
mânticas de autor como gênio criador, que foram brilhantemente formuladas no Primeiro Romantismo alemão, por Frühromantiker do calibre de Hölderlin, Goethe e os irmãos Schiller, em resposta estética à filosofia crítica de Immanuel Kant, que provocou verdadeira "revolução copernicana", como se diz, no pensamento ocidental. As ideias iniciais dos Frühromantiker, repletas de agudezas críticas e inovações, sofreram no entanto rápidas diluições e exageradas banalizações ao longo dos últimos séculos, e pouco se conhece, nos dias atuais, sobre a sofisticação e o caráter reflexivo desse pensamento. Mas ainda restam ecos, ainda que distorcidos, que insistem em permanecer em áreas interpretativas, como no caso da tradução. A questão da intenção autoral, além de ser totalmente datada, consiste em pura ficção, e é um tema bastante démodé para os estudos contemporâneos da tradução.

Quanto à preservação do "espírito” ou a captação do sentido a ser traduzido num poema, mencionado por Mao em sua abordagem idealista da tradução poética, vamos ver como poderia responder Berman:

Partir do pressuposto que a tradução é a captação do sentido, é separálo de sua letra, de seu corpo mortal, de sua casca terrestre. É optar pelo universal e deixar o particular. A fidelidade ao sentido opõe-se - como para o crente e o filósofo - à fidelidade à letra. Sim, a fidelidade ao sentido é obrigatoriamente uma infidelidade à letra.” (Berman, p. 32)

A articulação central de Berman, em seu livro A tradução e a letra, ou o albergue do longínquo é a defesa da fidelidade à letra, defesa da tradução "literalizante", que não se reduz à noção de tradução palavra a palavra - o que vai ser explicado por Berman a partir de análises de traduções “à letra” que considera de excepcional qualidade, como a tradução de Hölderlin da Antígona de Sófocles, entre outras. "A tradução literalizante", destaca Berman, constitui a face escondida, o continente negro da história da tradução ocidental” (Berman, p. 17). Ao desenvolver a noção de "tradução ética", aquela em que o tradutor se mantém em uma posição de equilíbrio entre o texto de partida e o texto de chegada, procurando não diferenciar seu foco de atenção em nenhum dos dois lados e considerando o aspecto literalizante do texto, não somente seu sentido, Berman afirma:

O objetivo ético do traduzir, por se propor acolher o Estrangeiro na sua corporeidade carnal, só pode estar ligado à letra da obra. Se a forma do objetivo é a fidelidade, é necessário dizer que só há fidelidade - em todas as áreas - à letra. Ser "fiel" a um contrato significa respeitar suas cláusulas, não o "espírito" do contrato. Ser fiel ao "espírito” de um texto é uma contradição em si. (2007:70)

O objetivo da tradução ética, de acordo com Berman, consiste em acolher na língua materna a literalidade carnal do texto, pois é nessa literalidade "que a obra desenvolve sua falância, sua Sprachlichkeit e realiza sua manifestação no mundo" (idem, p. 71).

Para Mao Dun, no entanto, o mais importante de se manter numa tradução de um poema é aquilo que Denham chama de "espírito sutil”, que seria o "sentido" do poema. A manutenção das rimas, do metro etc não seria, por sua vez, tão importante. Mao acredita que uma tradução muito boa pode ser feita 
com as ideias e o "espírito" do poema original. Nesse sentido, o autor destaca três condições para uma boa tradução por sentido: 1) não deve ser uma tradução resumida, deve manter todas as partes do poema original; 2) deve manter o "espírito" do poema original, o que seria, em suas palavras, a parte mais difícil de uma tradução; 3) a tradução deve seguir o estilo do poema original: "se o poema original é trágico e grandioso, a tradução não deve ser feita como algo leve e bonito. Afora isso, rima e metro etc são questões secundárias, e devem ser seguramente ignoradas” (Mao, 2004:206).

Uma vez que o esquema métrico fixo não poderá ser inteiramente seguido como no poema original, o que consistiria, de acordo com Mao, apenas numa imitação ${ }^{5}$ parcial, "seria melhor ignorar a forma e fazer uma tradução em prosa” (grifo nosso). E Mao Dun conclui seu artigo com a seguinte afirmação, em forma de conselho: "Creio que há uma regra com a qual devemos todos nos simpatizar: não se deve colocar muita ênfase em estar apto a reproduzir o esquema métrico do poema original” (Mao, 2004:207).

Como se percebe, a visão platônica de Mao Dun com relação à tradução poética o impede de contribuir com reflexões específicas sobre questões fônicas e sonoras entre idiomas ocidentais e o idioma chinês, desafio aparentemente ainda pouco enfrentado em termos teóricos na tradução de poesia da e para a língua chinesa. Por outro lado, a contribuição maior de Mao Dun é o crédito que dá a poesia e literatura de outras culturas, com a finalidade de enriquecer, revitalizar, eletrizar a nova literatura chinesa.

Raquel Abi-Sâmara raqsamara@gmail.com Profa. Dra., Universidade de Macau

\section{Referências bibliográficas}

Berman, Antoine. A tradução e a letra - ou o albergue do longínquo. Tradutores: Marie-Hélène Catherine Torres, Mauri Furlan, Andréia Guerini. Rio de Janeiro: 7Letras/PGET, 2007.

MAO Dun: "Some Thoughts on translating poetry” (1922). Translated by Brian Holton. In: Chan, Tak-hung Leo. Twentieth-Century Chinese Translation Theory. Amsterdam/Philadelphia USA: Benjamins Library, 2004.

\footnotetext{
${ }^{5}$ A escolha do termo “imitação” é coerente com suas noções de tradução como cópia, seja de sentido, seja aqui, no caso, de formas.
} 